\title{
A Modelagem Matemática no Ensino Fundamental: um estudo de pesquisas recentes
}

\section{Mathematical Modeling in Elementary School: a study of recente research}

\author{
Carlson Guerreiro de Almeida (cgalmeida@uesc.br) \\ Universidade Estadual de Santa Cruz (UESC) \\ Larissa Pinca Sarro Gomes (lpsgomes@uesc.br) \\ Universidade Estadual de Santa Cruz (UESC) \\ Zulma Elizabete de Freitas Madruga (betemadruga@ufrb.edu.br) \\ Universidade Federal do Recôncavo da Bahia (UFRB)
}

\begin{abstract}
Resumo: Objetiva-se verificar, nesse artigo, como os trabalhos que utilizam a Modelagem Matemática na perspectiva da Educação Matemática, como estratégia para o ensino e aprendizagem de estudantes do Ensino Fundamental, são apresentados no cenário investigativo brasileiro. Para que isso fosse possível, utilizou-se como procedimento metodológico o Mapeamento na Pesquisa Educacional. Os dados que fazem parte do corpus de análise foram coletados a partir de buscas realizadas no Catálogo de Teses e Dissertações da CAPES, nos últimos 10 anos, sendo analisados a partir de categorias a priori, definidas por: objetivo geral, público alvo, objeto matemático, dos problemas investigados/interesse de pesquisa, das concepções da Modelagem Matemática apresentadas, das metodologias utilizadas, dos principais resultados obtidos e das perspectivas de continuidade. Assim, por meio das três pesquisas selecionadas para análise, foi viável identificar as ações e reflexões, dos professores e estudantes, durante todo o processo de modelagem, bem como a participação e o desenvolvimento desses discentes no que diz respeito à construção dos conhecimentos matemáticos envolvidos no processo.
\end{abstract}

Palavras-chave: Modelagem Matemática; ensino e aprendizagem; mapeamento na pesquisa educacional.

Abstract: The objective of this article is to verify how the works that use Mathematical Modeling from the perspective of Mathematics Education, as a strategy for teaching and learning elementary school students, are presented in the Brazilian investigative scenario. To make this possible, Mapping in Educational Research was used as a methodological procedure. The data that are part of the analysis corpus were collected from searches carried out in the CAPES Thesis and Dissertations Catalog, of the last 10 years, being analyzed from a priori categories, defined by: general objective, target audience, mathematical object, the problems investigated / research interest, the mathematical modeling conceptions presented, the methodologies used, the main results obtained and the prospects for continuity. Thus, through the three researches selected for analysis, it was feasible to identify the actions and reflections, of teachers and students, during the entire modeling process, as well as the participation and development of these students with regard to the construction of the mathematical knowledge involved. in the process.

Recebido em: 18/01/2021

401

Aceito em: 24/02/2021 
Keywords: Mathematical Modeling; teaching and learning; mapping in educational research.

\section{INTRODUÇÃO}

Alguns pesquisadores em Matemática, com o intuito de apresentar alternativas para o ensino e, consequentemente, a aprendizagem da Matemática, começaram a desenvolver pesquisas na área da Educação Matemática. Essas pesquisas tinham como objetivo a contextualização de situações do cotidiano dos estudantes, trazendo-as para sala de aula, para que dessa forma fossem estabelecidas relações entre os saberes matemáticos contidos no currículo escolar e essas situações da realidade, facilitando, assim, a aprendizagem.

Desse modo, pode-se constatar que a Matemática está presente em toda a situacionalidade hodierna dos cidadãos, o que não difere do currículo escolar, o qual, desde os anos iniciais, traz a Matemática como disciplina essencial para o desenvolvimento acadêmico dos estudantes. Entretanto, sabe-se também que, muitos discentes apresentam algum tipo de dificuldade no processo de aprendizagem da referida disciplina, fato que levou pesquisadores da área da Educação Matemática a buscarem alternativas pedagógicas, as quais pudessem auxiliar no percurso do ensino e aprendizagem desse campo do conhecimento, a fim de aproximar a Matemática presente nos currículos escolares e ensinada em sala de aula, daquela presente no cotidiano.

Conforme tal entendimento, esses pesquisadores perceberam a importância da contextualização e de trazer situações do cotidiano dos estudantes, (re) significando-as e expressando-as por meio da linguagem matemática, para assim estabelecer relações entre a realidade dos estudantes e os conteúdos apresentados. A partir dessas investigações, foi identificada a necessidade de fomentar o pensamento matemático dos estudantes por meio de situações habituais, partindo do desenvolvimento, no campo da Educação Matemática, de pesquisas que apresentassem estratégias metodológicas, as quais pudessem contribuir com o ensino da Matemática, tendo por objetivo impactar a maneira de ensinar e aprender os conteúdos da área, no âmbito escolar.

Uma dessas estratégias metodológicas para o ensino da Matemática, e que há mais de 40 anos vem sendo pesquisada, é a Modelagem Matemática. No Brasil, as pesquisas em Modelagem Matemática foram impulsionadas por Aristides Camargo Barreto, 
Ubiratan D’Ambrosio e Rodney Carlos Bassanezi, sendo este último, o maior disseminador das pesquisas em modelagem.

Segundo Bassanezi (2010), a modelagem pode ser considerada tanto como um método voltado para a pesquisa quanto para o ensino, e ainda "[...] consiste na arte de transformar problemas da realidade em problemas matemáticos e resolvê-los interpretando suas soluções na linguagem do mundo real” (BASSANEZI, 2010, p.16).

Nesta perspectiva, realizou-se um mapeamento de teses e dissertações voltadas para a Educação Básica, de forma particular para o Ensino Fundamental, as quais apresentam, em seu pressuposto teórico, a Modelagem Matemática e a utilizam como estratégia metodológica para o ensino e a aprendizagem de Matemática. Portanto, procura-se nesse artigo responder a seguinte questão de pesquisa: como a modelagem, na perspectiva da Educação Matemática, apresenta-se em pesquisas acadêmicas que a utiliza como estratégia metodológica para o ensino e a aprendizagem de estudantes do Ensino Fundamental? Para isso, tem-se como objetivo verificar como os trabalhos, que utilizam a Modelagem Matemática, na perspectiva da Educação Matemática, como estratégia para o ensino e aprendizagem de estudantes do Ensino Fundamental, são apresentadas no cenário investigativo brasileiro.

\section{APORTE TEÓRICO}

A Modelagem Matemática é definida de diferentes formas e por diversos autores, como por exemplo: (BURAK, 1992; BARBOSA, 2001; MALHEIROS, 2004; BASSANEZI, 2010; BIEMBENGUT, 2016; ALMEIDA; DIAS, 2004; ARAÚJO, 2007; OLIVEIRA, 2010; ALMEIDA; SILVA; VERTUAN, 2013), os quais apresentam as concepções contemplando o ensino e a aprendizagem da Matemática. Desse modo, podese constatar que por meio da modelagem é possível estabelecer relações entre a Matemática e outras áreas do conhecimento, em que o professor atua como orientador, durante o processo de aprendizagem e o estudante como protagonista, no desenvolvimento do pensamento matemático, construindo novos conhecimentos, pois um dos objetivos da modelagem é transformar problemas reais, em problemas matemáticos.

Pesquisadores em Modelagem Matemática acreditam que, quando situações do mundo são contextualizadas e trazidas para a linguagem matemática, a aprendizagem ocorre com maior facilidade. 
Para Burak (1992) a modelagem é constituída por um conjunto de procedimentos, que tem como objetivo a construção de um paralelo, na tentativa de explicar, matematicamente, os fenômenos que fazem parte do cotidiano das pessoas, para que, a partir daí, decisões possam ser tomadas. Nessa mesma perspectiva, Blum e Niss (1991, p. 40) afirmam que “[...] o processo de modelagem é a prática de obter situações problema do cotidiano e relacioná-los com a Matemática”.

Na concepção de Barbosa (2001, p. 6), “[...] modelagem é um ambiente de aprendizagem no qual os alunos são convidados a indagar e/ou investigar, por meio da matemática, situações oriundas de outras áreas da realidade”. Para Malheiros (2004), a modelagem se configura como uma alternativa pedagógica em que, a partir de um tema ou problema, os estudantes, orientados pelo professor, buscarão a solução desse problema, por meio do uso dos conteúdos matemáticos.

E ainda, Almeida e Dias (2004) afirmam que a modelagem desperta um maior interesse e desenvolvimento do conhecimento crítico e reflexivo dos estudantes em relação aos conteúdos matemáticos, quando estes têm a oportunidade de identificar e estudar situações de sua realidade. Esses autores afirmam que a Modelagem Matemática pode proporcionar aos estudantes oportunidades de identificar e estudar situaçõesproblema de sua realidade, despertando maior interesse e desenvolvendo um conhecimento de modo mais pragmático e próximo da realidade. Para tanto, Bassanezi (2010) indica que a modelagem consiste num método que alia teoria e prática, que ao transformar situações do cotidiano em problemas matemáticos são obtidos resultados, os quais são usados para validação dos modelos matemáticos construídos durante o processo.

Assim como Bassanezi (2010), Biembengut (2016) conceitua a modelagem como um método voltado para pesquisa e também para o ensino. A autora define a modelagem como método que objetiva a promoção do conhecimento do estudante por meio da pesquisa, através da qual o professor estimula o estudante à investigação no ambiente escolar e isso pode ocorrer em qualquer nível de escolaridade. E ainda, segundo Biembengut e Hein (2011), a modelagem se caracteriza como um método de ensino e aprendizagem, cujas questões são desenvolvidas a partir de uma situação/tema, sendo respondidas por meio dos conteúdos matemáticos e de pesquisas sobre o tema proposto. 
Biembengut (2016) apresenta ainda uma concepção da modelagem mais voltada para a sua utilização na Educação Básica, denominada de Modelagem na Educação Modelação, que tem como objetivo promover o conhecimento do estudante, ajudando-o a realizar pesquisa no ambiente escolar, em qualquer nível de escolaridade. Para a autora,

\begin{abstract}
A Modelação é um método de ensino com pesquisa nos limites e espaços escolares, em qualquer disciplina e fase de escolaridade: dos Anos Iniciais do Ensino Fundamental aos Finais do Ensino Superior e, ainda, em Cursos de formação continuada ou disciplina de pós-graduação (BIEMBENGUT, 2016, p. 177).
\end{abstract}

Segundo Biembengut (2016) por meio da modelagem, o professor pode ensinar os conteúdos, presentes no currículo escolar, aos estudantes, e além disso, podem orientar esses estudantes no processo de aprendizagem por meio de pesquisas. Desse modo, a Modelagem Matemática pode ser apresentada como uma estratégia para o ensino e a aprendizagem, desde a Educação Básica até o Ensino Superior, proporcionando que sejam abordadas situações do cotidiano, por meio dos conteúdos matemáticos.

\title{
3. PERCURSO METODOLÓGICO
}

A presente investigação assume uma abordagem qualitativa, pois segundo Bogdan e Biklen (2010), o ambiente natural é a fonte de dados, além de possuir um caráter descritivo, tomando por base o levantamento de dados realizado por meio de produções escritas. A pesquisa é de cunho bibliográfico analítico, que segundo Gil (2008) sua constituição ocorre a partir da coleta de informações advindas de livros e artigos científicos, o que possibilita um alcance mais amplo dos dados, por parte do pesquisador.

Como procedimento metodológico para a construção dessa pesquisa, assumiu-se a concepção defendida por Biembengut (2008), o Mapeamento na Pesquisa Educacional, em que a autora o define como um conjunto de ações que se inicia com a identificação dos dados, logo após acontece o levantamento, a classificação e a organização desses dados envolvidos com a questão a ser pesquisada, e por fim, as suas análises.

A coleta dos dados que compõe as análises dessa pesquisa, ocorreu por meio de buscas realizadas no ambiente virtual, na rede mundial de computadores - a Internet, em sites de base científica. Essas buscas objetivaram a obtenção de teses e dissertações, que utilizaram a MM como estratégia para o ensino e aprendizagem de Matemática, tendo por público alvo estudantes do Ensino Fundamental. 
Para tanto, realizou-se o mapeamento a partir de investigações no Catálogo de Teses e Dissertações da Coordenação de Aperfeiçoamento de Pessoal de Nível Superior (CAPES), buscando a expressão exata “Modelagem na Educação", sendo obtidas 1.022.666 pesquisas, distribuídas em 51.134 páginas, voltadas para diversas áreas do conhecimento.

Como o portal da CAPES oferece filtros de buscas que auxiliam na obtenção de pesquisas específicas correspondentes ao objeto pesquisado e dentre esses filtros, ofertados no portal, foram utilizados os referentes a: 'Tipo de Pesquisa', 'Ano de Publicação', 'Grande Área do Conhecimento', ‘Área de Conhecimento', 'Área de Avaliação', 'Área de Concentração' e por último 'Nome do Programa'.

Ao utilizar o filtro correspondente ao 'Tipo de pesquisa', selecionou-se os itens Doutorado (teses) e Mestrado (dissertação), sendo encontradas 942.245 pesquisas. O próximo filtro utilizado, denominado 'Ano', optou-se pela busca de pesquisas que tivessem sido publicadas nos últimos 10 anos, ou seja, entre os anos de 2010 e 2019, sendo encontradas 548.716 pesquisas. No filtro seguinte, 'Grande Área do Conhecimento', foram escolhidos os itens Ciências Exatas e da Terra e Multidisciplinar, assim foram encontradas 95.403 pesquisas.

Dando continuidade à utilização dos filtros oferecidos, optou-se pela seleção de ‘Área de Conhecimento', em que foram selecionados os itens Ensino, Ensino de Ciências e Matemática e Matemática, tendo como resultado 9.817 pesquisas. O próximo filtro, ‘Área de Avaliação', foi escolhido o item correspondente à Ensino, sendo encontradas 8.330 pesquisas. O filtro seguinte, 'Área de Concentração', oferecia diversos itens para filtragem, porém optou-se por selecionar: Ciências e Matemática, Educação Básica, Educação em Ciências e Matemática, Educação Matemática, Cultura e Diversidade, Ensino, Ensino de Ciências e Matemática, Ensino de Ciências e Educação Matemática, Ensino de Matemática e Ensino na Educação Básica. Após essas seleções totalizaram 3.015 pesquisas.

Por fim, o último filtro utilizado nas buscas, denominado 'Nome do Programa', dos diversos itens apresentados, foram selecionados: Educação em Ciência e Matemática, Educação Matemática, Educação Matemática e Tecnológica, Educação para a Ciência e a Matemática, Ensino, Ensino de Ciências e Matemática, Ensino de Ciências e Educação Matemática, Ensino de Matemática, Ensino na Educação Básica, Educação Matemática 
e Ensino de Física, Educação em Ciências e em Matemática, com isso foram encontradas 2.331 pesquisas.

Após a utilização dessas opções de filtragens restaram 2.331 pesquisas que tiveram seus títulos, palavras-chave e resumos lidos para que fossem selecionadas apenas as pesquisas que abordassem a Modelagem Matemática como estratégia para o ensino e aprendizagem de Matemática com estudantes da Educação Básica, em quaisquer um desses itens. Ao término dessas leituras, restaram 20 pesquisas que obedeciam a esse critério.

Como o interesse da pesquisa são os trabalhos que têm como foco o Ensino Fundamental, foram feitas leituras mais criteriosas, com o intuito de selecionar somente aqueles que obedecessem a esse parâmetro. Com isso, as pesquisas que compuseram o corpus de análise desse trabalho, serão apresentadas, em seguida, no Quadro 1.

Quadro 1 - Mapeamento de Pesquisas.

\begin{tabular}{|c|c|c|c|}
\hline Identificação & Título & Autor & $\begin{array}{l}\text { Tipo de } \\
\text { Pesquisa }\end{array}$ \\
\hline P1 & $\begin{array}{l}\text { A PERSPECTIVA DA CRIANÇA EM } \\
\text { ATIVIDADES DE MODELAGEM } \\
\text { MATEMÁTICA NOS ANOS INICIAIS }\end{array}$ & $\begin{array}{l}\text { LÍLIA CRISTINA } \\
\text { DOS SANTOS } \\
\text { DINIZ ALVES }\end{array}$ & $\begin{array}{l}\text { DISSERTAÇÃ } \\
\text { O }\end{array}$ \\
\hline CVISta & $\begin{array}{c}\text { EDUCAÇÃO DO CAMPO E } \\
\text { MODELAGEM MATEMÁTICA: } \\
\text { CONSTRUÇÃO DE ESTUFA PARA A } \\
\text { PRODUÇÃO DE ORGÂNICOS NA } \\
\text { ZONA RURAL DE SÃO SEBASTIÃO } \\
\text { DO CAÍ }\end{array}$ & $\begin{array}{c}\text { LISIANE SANTOS } \\
\text { FLORES }\end{array}$ & $\begin{array}{c}\text { DISSERTAÇA } \tilde{A} \\
\mathrm{O}\end{array}$ \\
\hline P3 & $\begin{array}{c}\text { PROJETO DE MODELAGEM } \\
\text { MATEMÁTICA E TEOREMAS EM } \\
\text { AÇÃO: UMA INVESTIGAÇÃO SOBRE } \\
\text { OS CONCEITOS DE ÂREA E } \\
\text { PERÍMETRO }\end{array}$ & $\begin{array}{c}\text { ROZÉLY XAVIER } \\
\text { ROSA }\end{array}$ & $\begin{array}{c}\text { DISSERTAÇÃ } \\
\mathrm{O}\end{array}$ \\
\hline
\end{tabular}

Fonte: Dados da pesquisa.

Analisou-se as pesquisas selecionadas levando em consideração categorias a priori, definidas por: objetivos gerais, o público-alvo da pesquisa e objeto matemático estudado; os problemas investigados/interesses da pesquisa; as concepções da Modelagem Matemática apresentadas; metodologias utilizadas nas pesquisas; principais resultados obtidos; e perspectivas de continuidade. Os principais pontos emergentes desta análise são descritos a seguir.

\section{RESULTADOS E DISCUSSÃO}


Nesta etapa da investigação, reúnem-se os resultados obtidos em cada pesquisa, com a produção teórica pertinente a cada categoria.

\subsection{Objetivos gerais, público-alvo da pesquisa e objeto matemático estudado}

No Quadro 2 serão apresentados os itens analisados nas três pesquisas selecionadas.

Quadro 2 - Objetivo Geral, Público Alvo e Objeto Matemático presentes nas pesquisas.

\begin{tabular}{|c|c|c|c|}
\hline Pesquisa & Objetivo Geral & $\begin{array}{c}\text { Público } \\
\text { Alvo }\end{array}$ & Objeto Matemático \\
\hline $\mathrm{P} 1$ & $\begin{array}{l}\text { Constituir uma atividade de modelagem com criança e na } \\
\text { perspectiva dela, dando voz e vez às crianças na } \\
\text { constituição da atividade de Modelagem Matemática, } \\
\text { respeitando seus modos de ser e estar no mundo. }\end{array}$ & $1^{\circ}$ ano & $\begin{array}{l}\text { Medidas de } \\
\text { comprimento } \\
\text { Números } \\
\text { Operações }\end{array}$ \\
\hline $\mathrm{P} 2$ & $\begin{array}{l}\text { Identificar, sob a ótica da Educação Matemática Crítica, } \\
\text { as contribuições dos ambientes de aprendizagens } \\
\text { promovidos pela Modelagem Matemática para o } \\
\text { desenvolvimento de competências e habilidades } \\
\text { matemáticas dos estudantes do oitavo e nono ano da } \\
\text { Escola Thomé. }\end{array}$ & $\begin{array}{c}8^{\circ} \text { e } 9^{\circ} \\
\text { anos }\end{array}$ & Geometria \\
\hline P3 & $\begin{array}{l}\text { Investigar a existência, ou não, de teoremas em ação falsos } \\
\text { manifestados nas respostas de estudantes, do } 6^{\circ} \text { ao } 9^{\circ} \text { ano } \\
\text { do Ensino Fundamental de uma escola do campo, } \\
\text { mediante questões contextualizadas e em um projeto de } \\
\text { Modelagem Matemática, envolvendo os conceitos de área } \\
\text { e perímetro. }\end{array}$ & $\begin{array}{c}6^{\circ} \text { ao } 9^{\circ} \\
\text { ano }\end{array}$ & Área e Perímetro \\
\hline
\end{tabular}

Fonte: Dados da Pesquisa.

Na pesquisa $\mathrm{P} 1$, os participantes eram crianças com idade entre 5 e 8 anos, que integravam uma das turmas do $1^{\circ}$ ano do Ensino Fundamental, turma esta composta por 23 crianças, mas participaram do processo de investigação somente 16.

As pesquisas P2 e P3 foram desenvolvidas com estudantes dos anos finais do Ensino Fundamental. Na P2 participaram 35 estudantes, sendo que 19 eram do oitavo ano e 16 eram do nono ano. Esses estudantes eram oriundos de duas turmas do oitavo ano e uma turma do nono ano.

A participação na P3 foi constituída por 18 estudantes, os quais cursavam os anos finais do Ensino Fundamental, sendo que três estavam no sexto ano, quatro eram do sétimo ano, quatro do oitavo ano e sete eram do nono ano.

Os autores, em suas pesquisas, preocupam-se com o ensino e aprendizagem dos conteúdos matemáticos, constantes no currículo da Educação Básica, desenvolvidos por meio da Modelagem Matemática. Cada pesquisa elencada auxilia na compreensão deste artigo, o qual objetiva analisar trabalhos que usam a modelagem como estratégia, em sala 
de aula, para o ensino e aprendizagem de Matemática com estudantes do Ensino Fundamental. No entanto, observa-se que há poucas investigações para esse público-alvo, o que indica a necessidade de desenvolvimento de mais pesquisas com esse enfoque.

\subsection{Problemas investigados/interesse de pesquisa}

As três pesquisas selecionadas apresentam questionamentos e motivações que as levaram à investigação com referência à Modelagem Matemática e suas contribuições no processo de ensino e aprendizagem da Matemática na Educação Básica, e, de maneira especial, no Ensino Fundamental.

Na P1, a autora ao participar de um projeto de expansão, durante a graduação em Licenciatura em Matemática, percebeu a defasagem de metodologias para o ensino de Matemática com crianças. Ela percebeu os desafios em realizar pesquisas com crianças, e a necessidade de dar-lhes visibilidade no sentido de essas crianças poderem expor suas falas, expressões, sentimentos e gestos. Nesse sentido, a autora se propôs a desenvolver uma atividade em Modelagem Matemática, no qual as crianças atuassem de forma participativa durante todo o processo.

Em P2, a autora realizou um levantamento a respeito dos rendimentos dos estudantes do oitavo ano da escola, na qual a mesma era a professora, e ao verificar o baixo desempenho desses estudantes, identificou nos ambientes de aprendizagem, proporcionados pela Modelagem Matemática, uma possiblidade de desenvolver habilidades e competências que promovessem autonomia no fazer, no aprender e no reaprender e lhes dessem alternativas para a construção de novos conhecimentos, respeitando os conhecimentos que eles já possuíam.

$\mathrm{Na}$ P3, a autora procurou identificar as estratégias utilizadas pelos estudantes, envolvidos na pesquisa, para solucionar um problema, levando em consideração possibilidades de erros durante o processo de Modelagem e de resolução das atividades desenvolvidas nesse processo. A autora compreendeu a possibilidade de o estudante, por meio do erro, ser capaz de desenvolver e construir seus conhecimentos.

Em todas as pesquisas apresentadas, existe uma preocupação das autoras em analisar as reflexões, impressões e ações dos estudantes durante o processo de ensino e aprendizagem de Matemática, por meio da Modelagem Matemática, apresentando assim, algumas concepções e abordagens da modelagem. 
Os problemas de pesquisas constituídos nos trabalhos analisados acordam com a perspectiva de um ensino de Matemática contextualizado, onde as autoras preocupam-se com o envolvimento dos estudantes durante o processo, e que esses tenham autonomia na construção do conhecimento. Na perspectiva da Educação Matemática, a modelagem se configura como uma estratégia capaz de inserir os estudantes no processo de ensino e aprendizagem da construção dos conteúdos matemáticos.

\subsection{As concepções da Modelagem Matemática apresentadas}

As três pesquisas estão sustentadas nas concepções defendidas por Barbosa (2001, 2004), Burak (1992, 2004) e Burak e Kluber (2008), em que o primeiro define a modelagem como um ambiente de aprendizagem, através do qual os alunos são convidados à investigação de situações reais por meio da Matemática, podendo estes aceitarem ou não participar desse processo investigativo; e o segundo a define como um conjunto de procedimentos que objetiva explicar, matematicamente, situações do cotidiano. Portanto, as pesquisas analisadas estão amparadas em uma dessas duas concepções para a utilização da Modelagem Matemática em sala de aula.

As pesquisas P1 e P3 utilizam as etapas sugeridas por Burak $(1992,2004)$ e Burak e Kluber (2008), que correspondem a: Escolha do Tema, procedimento em que o professor apresenta aos estudantes alguns temas para investigação ou os próprios estudantes sugerem aqueles que sejam de seu interesse, sendo que, não necessariamente precisem estar relacionados à Matemática ou aos conteúdos matemáticos; Pesquisa Exploratória, nessa etapa, após a escolha do tema, os estudantes buscam informações a respeito do que será investigado; Levantamento dos Problemas, após a coleta dos dados, acerca do tema investigado, os estudantes são incentivados a estabelecer relações dessas informações com a Matemática e a elaborarem problemas que possibilitem a aplicação e aprendizagem dos conteúdos matemáticos; Resolução dos Problemas e Desenvolvimento do Conteúdo Matemático, nessa etapa, os estudantes, por meio do uso dos conteúdos matemáticos, irão procurar soluções para os problemas que geraram a investigação, fazendo uso das informações coletadas na etapa da pesquisa exploratória; e Análise Crítica das Soluções, nesse momento do processo é realizada uma apreciação das soluções encontradas para o problema proposto, bem como as considerações e as análises das hipóteses consideradas na etapa de levantamento dos problemas, verificando a 
coerência no que diz respeito à matemática utilizada para responder às hipóteses levantadas.

E na P2, a autora se sustenta no método concebido por Barbosa (2001), o qual defende a participação do estudante de forma conjunta com o professor, durante o processo de ensino e aprendizagem. Para o autor, durante o processo de Modelagem, os estudantes são levados a explorar e investigar problemas de sua realidade e esses problemas não, necessariamente, precisam ser matemáticos, porém exigem competências e habilidades matemáticas para resolvê-los. Nessa perspectiva, esse ambiente de aprendizagem pode propiciar aos estudantes possibilidades para a construção do conhecimento matemático e sua participação, durante o processo de investigação, contribui para a sua formação reflexiva perante outros contextos, que não somente os matemáticos.

Barbosa (2001) apresenta três possíveis casos de investigação por meio da Modelagem Matemática, no contexto escolar, os quais serão expostos a seguir: no Caso 1, cabe ao professor desde a escolha do tema a ser pesquisado aos métodos que serão utilizados pelo estudante, para resolução do problema apresentado. No Caso 2, o professor é o responsável pela elaboração do tema proposto na pesquisa, cabendo aos discentes, caso aceitem participar do processo de investigação, atuarem como coautores no processo e na resolução do problema proposto. E por fim, no Caso 3, professor e estudantes atuam no processo desde a escolha do tema a ser investigado, determinando os métodos que serão utilizados durante a investigação, até a resolução do problema proposto. A autora da P2 deixa evidente que a pesquisa assume características do Caso 2, sugerindo a escolha do tema a ser investigado e os estudantes, após aceitaram a participação no processo, desenvolveram-no de forma equitativa.

A intenção ao ponderar as pesquisas que fazem parte do corpus de análise desse trabalho foi a de identificar, dentre as diversas concepções existentes a respeito da Modelagem Matemática, aquelas utilizadas pelos autores.

Fica evidente que, as autoras preocuparam-se em utilizar as concepções da modelagem que defendem a sala de aula como um ambiente de aprendizagem, onde o professor, em conjunto com os estudantes, por meio da investigação de temas matemáticos ou não, desenvolve o conteúdo matemático pretendido na escolha do problema a ser investigado. Nas três pesquisas analisadas, são sugeridos temas, e os 
estudantes, tendo os pesquisadores como mediadores, por meio de investigação, levantamentos de dados, conhecimentos prévios, participam da construção do conhecimento de forma colaborativa e cooperativa, obtendo a solução do problema gerado.

\subsection{Metodologias utilizadas nas pesquisas}

As três autoras assumem uma abordagem qualitativa em suas pesquisas, o que é bastante comum em investigações produzidas no campo da Educação Matemática, pois numa pesquisa qualitativa, segundo Bogdan e Biklen (2010), os dados são classificados como qualitativos, e durante o processo de investigação todas as etapas ocorridas são descritas de forma detalhada. $\mathrm{O}$ interesse do investigador está centrado mais no processo do que nos resultados, sendo comum a apuração dos dados que compõem a investigação, de forma indutiva.

Bogdan e Biklen (2010) afirmam que na pesquisa qualitativa os resultados numéricos não são priorizados, mas se leva em consideração o aprofundamento da compreensão de um grupo social, entre outros. Este tipo de pesquisa está relacionado ao levantamento de dados, bem como a compreensão e interpretação do comportamento de um determinado grupo. Desse modo, Bogdan e Biklen (2010, p. 17) asseveram que "[...] o investigador frequenta os locais em que naturalmente se verificam os fenômenos nos quais está interessado, incidindo os dados recolhidos nos comportamentos naturais das pessoas".

Das pesquisas selecionadas para análise, as autoras das P2 e P3 eram professoras e pesquisadoras, fazendo do espaço escolar seu espaço empírico. Apenas a autora da P1 não era professora da turma participante do processo de investigação e o espaço escolar, no qual a pesquisa fora realizada, não era seu ambiente de trabalho.

Pode-se observar que nas três pesquisas analisadas aparecem a prática em sala de aula, e essa participação direta e/ou participante dos pesquisadores é uma eficaz fonte de coleta de dados, quando se trata de uma pesquisa qualitativa. Em vista disso, na P1, a autora evidencia que a metodologia de pesquisa que mais se aproxima e orienta sua investigação, do ponto de vista teórico-metodológico, é a pesquisa com crianças, que segundo Silvestri (2015, p. 4), “[...] é desse lugar que podemos produzir reflexões - 
apenas reflexões -, pois uma metodologia de pesquisa com crianças ainda está por ser sistematizada, se é que isso possa ser feito".

Já as P2 e P3 estão caracterizadas como pesquisas participantes, que segundo Peruzzo (2003, p. 2), “consiste na inserção do pesquisador no ambiente natural de ocorrência do fenômeno e de sua intenção com a situação investigada". Para o autor, a presença do pesquisador no ambiente investigado tem que ser constante, para que todo o processo seja observado de dentro, deve haver o seu envolvimento em todas as atividades da pesquisa, fazendo-se necessário que assumam o papel do participante, de modo que o pesquisado compreenda o sentido das suas ações.

\subsection{Principais resultados obtidos}

No que diz respeito aos resultados obtidos com as pesquisas, a autora da P1 relata que a modelagem proporcionou relevâncias tanto à prática pedagógica do professor quanto ao conteúdo matemático apresentado, e vislumbrou possibilidades de interdisciplinaridade entre a Matemática e outras áreas do conhecimento, como por exemplo: a literatura infantil e as artes.

A autora da P2 expõe que o uso da modelagem promoveu a construção de novos conhecimentos pelos estudantes, já que estes participaram de todo o processo investigativo, de forma equitativa com o professor, e além disso, auxiliou no desenvolvimento e entendimento crítico e democrático dos estudantes.

$\mathrm{Na}$ P3, a autora apresenta em suas conclusões que, ao se depararem com o uso da Modelagem Matemática, os estudantes conseguiram desenvolver o conceito dos conteúdos matemáticos de forma mais significativa, uma vez que precisam utilizá-los numa situação real, ou seja, na prática. Assim, os estudantes ao serem confrontados com situações reais, perceberam a necessidade da utilização dos conceitos matemáticos para a resolução do problema.

As três pesquisas indicam que o uso da Modelagem Matemática em sala de aula, proporcionaram aos estudantes um envolvimento em todo processo investigativo, bem como na construção dos novos conhecimentos matemáticos propostos. Em suas pesquisas, as autoras indicam possibilidades de contribuições para que outras investigações possam vir a serem desenvolvidas, tanto na mesma temática quanto em outras temáticas, mas que possuam vertentes similares às suas pesquisas. As autoras 
evidenciam o quanto as pesquisas podem auxiliar às práticas dos professores da Educação Básica e indicam também possibilidades de continuidade em suas investigações.

\subsection{Perspectivas de continuidade}

Em pesquisas acadêmicas, alguns autores recomendam perspectivas de continuidade para o tema pesquisado, indicando a possibilidade da exploração do tema até mesmo por outros pesquisadores. E essa continuidade de pesquisa, por sua vez, pode acontecer na mesma temática ou por meio de outras vertentes. Isto posto, das pesquisas apresentadas, apenas a autora da P3 suscitou outros aspectos merecedores de investigações. Já nas P1 e P2 não houve indicações para continuidade dos estudos por parte das autoras.

A autora da P3 apontou para a possibilidade de a pesquisa desenvolvida contribuir para futuras investigações, que contemplem a temática proposta, além de sugerir que sejam realizadas novas pesquisas a respeito dos conteúdos matemáticos, os quais foram investigados e das estratégias metodológicas desenvolvidas durante o processo de ensino e aprendizagem.

\section{CONSIDERAÇÕES}

O objetivo dessa pesquisa foi verificar como os trabalhos que utilizam a Modelagem Matemática na perspectiva da Educação Matemática, como estratégia para o ensino e aprendizagem da Matemática de estudantes do Ensino Fundamental, são apresentadas no cenário investigativo brasileiro. Assim, amparados pela metodologia do Mapeamento na Pesquisa Educacional (BIEMBENGUT, 2008), foram selecionadas e analisadas pesquisas que se adequam aos critérios estabelecidos.

Nas pesquisas selecionadas para estudo estão presentes as concepções existentes a respeito da Modelagem Matemática na perspectiva da Educação Matemática, as percepções de suas autoras a respeito dessas concepções que constituíram o desenvolvimento de suas pesquisas, suas compreensões acerca das contribuições acarretadas pelo uso da modelagem nas atividades desenvolvidas em sala de aula, e a aprendizagem e também participação dos estudantes durante todo o processo de construção dos novos conhecimentos matemáticos.

Todas as pesquisas apresentaram como participantes, estudantes dos Anos Iniciais e/ou Finais do Ensino Fundamental, e obtiveram como resultado que o uso da Modelagem 
Matemática proporcionou a esses estudantes a possibilidade de envolvimento durante o processo de ensino, facilitando a sua aprendizagem, atendendo o objetivo da modelagem que é trazer para o espaço da sala de aula, situações que acontecem no cotidiano desses estudantes.

Em todas as pesquisas, as autoras evidenciaram a relevância do uso da Modelagem Matemática nas práticas pedagógicas, suas contribuições na capacitação e na qualificação dos estudantes, bem como a sua importância como uma alternativa metodológica para o processo de ensino e aprendizagem. As autoras descrevem a participação dos estudantes durante o percurso de investigação e o envolvimento destes durante a construção dos conteúdos matemáticos, que foram objetos da pesquisa.

Com isso, faz-se necessário a divulgação de pesquisas que defendam a utilização da modelagem em sala de aula, pois entende-se que o seu uso traz benefícios no processo de aprendizagem dos estudantes, em todos os níveis de formação do sistema escolar.

Após a leitura e análise dessas pesquisas, pode-se compreender a importância do uso de alternativas metodológicas, em particular da Modelagem Matemática, no desenvolvimento de atividades em sala de aula. Pode-se observar que, quando são levadas situações do cotidiano dos estudantes, de maneira contextualizada, para que esses resolvam por meio da modelagem, isto proporciona a esses estudantes autonomia na construção do conhecimento matemático. É dado ao estudante, possibilidades de eles perceberem, por meio dessas atividades, o uso do conteúdo matemático aprendido na escola, em sua vida fora do ambiente escolar, proporcionando ao ensino e a aprendizagem de Matemática, maior significado, além de aprimorar seus conhecimentos prévios.

Portanto, evidencia-se aqui a importância da realização desse mapeamento, com a finalidade de trazer ao conhecimento, de pesquisadores da Educação Matemática e professores de Matemática, investigações que vêm sendo desenvolvidas no cenário acadêmico brasileiro, com abordagem em estratégias pedagógicas e metodológicas para o ensino da Matemática, de forma especial a Modelagem Matemática na perspectiva da Educação Matemática e suas contribuições na aprendizagem dos estudantes da Educação Básica, em particular, do Ensino Fundamental.

\section{REFERENCIAS}


ALMEIDA, L. M. W.; DIAS, M. R. Um estudo sobre o uso da Modelagem Matemática como estratégia de ensino e aprendizagem. Revista Bolema, UNESP de Rio Claro, ano 17, n.22, p. 19-35, 2004.

ALMEIDA, L. M. W; SILVA, K. P. da; VERTUAN, R. E. Modelagem Matemática na Educação Básica. São Paulo: Editora Contexto, 2013.

ALVES, L. C. dos S. D. A perspectiva da criança em atividades de Modelagem Matemática nos Anos Iniciais. 2018. 131f. Dissertação (Mestrado em Educação em Ciências e Matemática). Instituto de Educação Matemática e Científica. Universidade Federal do Pará, Belém.

ARAÚJO, J. de L. Relação entre Matemática e realidade em algumas perspectivas de modelagem matemática na Educação Matemática. In: BARBOSA, J. C.; CALDEIRA, A. D.; ARAÚJO, J. de L. (Org.) Modelagem Matemática na Educação Matemática Brasileira: pesquisas e práticas educacionais. Recife: Sociedade Brasileira de Educação Matemática, 2007, p. 17-32.

BARBOSA, J. C. Modelagem Matemática: contribuição para o debate teórico. In: Reunião Anual da ANPED, 24, 2001, Caxambu, Anais... Rio de Janeiro: ANPED, 2001.1 CD-ROM. 2004.

Modelagem Matemática: O que é? Por que? Revista Veritati, n.4, p.73-80,

BASSANEZI, R. C. Ensino-aprendizagem com Modelagem Matemática: uma nova estratégia. 3ed. $2^{a}$ reimpressão. São Paulo: Contexto, 2010.

BIEMBENGUT, M. S. Mapeamento na Pesquisa Educacional. Rio de Janeiro: Editora Ciência Moderna, 2008.

Modelagem na Educação Matemática e na Ciência. São Paulo: Editora Livraria da Física, 2016.

BIEMBENGUT, M. S.; HEIN, N. Modelagem Matemática no ensino. São Paulo: Editora Contexto, 2011.

BLUM, W.; NISS, M. Applied mathematical problem solving, modelling, applications, and links to other subjects-state, trends and issues in mathematics instruction. Educational Studies in Mathematics, Dordrecht, v.22, n.1, p.37-68, 1991.

BOGDAN, R.; BIKLEN, S. K. Investigação Qualitativa em Educação: uma introdução à teoria e aos métodos. Lisboa: Porto Editora, 2010.

BURAK, D. Modelagem Matemática: ações e interações no processo de ensino aprendizagem. Tese (Doutorado em Educação). FE/UNICAMP, Campinas, 1992. 
Modelagem matemática e a sala de aula. In: ENCONTRO PARANAENSE DE MODELAGEM EM EDUCAÇÃO MATEMÁTICA, 1, 2004, Londrina, Anais... Londrina: [S.I]. 1 CD-ROM.

BURAK, D.; KLÜBER, T. E. Educação Matemática: contribuições para a compreensão da sua natureza. Acta Scientiae, v. 10, n. 2, p. 93-106, 2008.

FLORES, L. S. Educação do Campo e Modelagem Matemática: construção de estufa para a produção de orgânicos na Zona Rural de São Sebastião do Caí. 2019. $105 f$. Dissertação (Mestrado em Ensino de Matemática). Instituto de Matemática e Estatística. Universidade Federal do Rio Grande do Sul, Porto Alegre.

GIL, A. C. Como elaborar projetos de pesquisa. 4ed. São Paulo: Atlas, 2008.

MAlheiros, A. P. S. Produção Matemática dos Alunos em Ambiente de Modelagem. 2001. 194f. Dissertação (Mestrado em Educação Matemática). Instituto de Geociências e Ciências Exatas, UNESP, Rio Claro, 2004.

PERUZZO, C. M. K. Da Observação Participante à Pesquisa-Ação em Comunicação: pressupostos epistemológicos e metodológicos. XXVI Congresso Brasileiro de Ciências da Comunicação - BH/MG - 2 a 6 Set 2003.

ROSA, R. X. Projeto de Modelagem Matemática e Teoremas em Ação: uma investigação sobre os conceitos de área e perímetro. 2017. 124f. Dissertação (Mestrado em Educação para a Ciências e a Matemática). Centro de Ciências Exatas. Universidade Estadual de Maringá, Maringá.

SILVESTRI, M. Sala de aula inventada o que se (re) cria com as crianças. In: reunião nacional da ANPED, 37, 2015, Florianópolis. Anais... Florianópolis, SC: UFSC. 